\title{
The Analysis of the Difference in Eco-friendly Behavior between Korean and Chinese Consumers
}

\author{
Jiyoung Yoon 1 )
}

\begin{abstract}
Global interest in environmental issues is increasing. Especially, the unusual climate phenomena and pollution problems on Earth, which are becoming serious in recent years, have gone beyond mere concerns. Accordingly, the Korean government has introduced various policies that take into account the environment, and many changes are taking place in consumer behavior and consciousness. However, the environmental issues are not a problem that can be solved in one country, but a problem that the world must overcome. This study was conducted on consumers in Korea and China who have environmental connections in the vicinity of the region, considering that academic research on the antecedents affecting consumers' eco-friendly behavior is necessary. For this purpose, the study examined the effects of environmental knowledge, environmental attitude, and cultural background variables on eco-friendly behavior of 210 Korean consumers living in Seoul and 198 Chinese consumers living in Shanghai, looking at differences in environmental knowledge, environmental attitudes and cultural background variables affecting eco-friendly behavior. The results of this study can be used as basic data on environmental policies in each country. It is also expected that the direction of the company's eco-friendly marketing strategy will have a positive effect.
\end{abstract}

Keywords: Eco-friendly, Behavior, Consciousness, Environmental, Attitude, Cultural, Background

\section{Introduction}

The benefits of modern civilization that people enjoy are not only positive but also negative. The climate and environmental pollution on the earth, which have become increasingly serious in recent years, they are at a level of considerable concern.

The suspension of plastic waste collection recycling in Korea in April 2018 caused many people to panic when China, which imported more than 50 percent of the waste, abruptly halted imports of 24 types of recycled products, such as plastic and waste. The Chinese government's strong stance on the ban on imports of waste was changed because of the new environmental protection law enacted in China in 2015. China is showing a sharp interest in

Received(September 26, 2019), Review Result(1st: October 21, 2019, 2nd: December 19, 2019), Accepted(January 30, 2020)

1) (Adjunct Professor) 03760 Dept of Consumer Studies, Ewha Womans University, 52, Ewhayeodae-gil, Seodaemun-gu, Seoul, Korea.

email: gkeducare1@gmail.com 
environmental problems compared to the past, and has begun to implement innovative environmental problems measures through the 'New Environmental Law'[1]. In fact, China, which is very geographically close to Korea, can have a great impact on environmental problems. For example, air pollution problems such as fine dust are also mentioned as very important cooperation between Korea and China[2]. And the Korean government, which has been aware of this crisis, introduced environmental measures to reduce plastic emissions by more than $50 \%$ by 2030[3]. And the policy to prevent the use of disposable cups was introduced in cafeteria and other stores, and the change of policy considering this environment changed the way of life of ordinary consumers.

In particular, environmental problems are not only a matter of one country, but the serious issue that the world should cope with. In this regard, many countries around the world have introduced policies and laws related to eco-friendly consumption, and the interest in eco-friendly research is increasing. However, most of the previous studies have shown to focus on the final solution of the disposal process rather than on the impact of eco-friendly behavior. Also, at the time when many consumers are interested in environmental problems recently, academic research on the relationship between antecedent variables affecting consumers' eco-friendly behavior is needed[4].

Therefore, this study aims to conduct a comparative study on the correlation between variables affecting "eco-friendly behavior" of consumers on Korea and China which have geographically close connection. The empirical verification process of the comparative research between countries targeting consumers of both countries will have practical academic implications[5]. The results of this study will provide basic data on environmental policies in Korea and China, and moreover expected that it will have a positive effect on the direction of eco-friendly marketing strategies of companies.

\section{Literature Review}

\subsection{Eco-friendly Behavior}

Since eco-friendly behavior is an act that contributes to environmental protection or management[4], it means that individuals act by considering environmental conservation and ecosystem balance rather than aiming for convenience of their needs[5]. This means that the individual behavior moves in consideration of the impact of the society and the environment[3]. Most of the studies focused on improving individual behavior into eco-friendly behavior define 
eco-friendly behavior as everyday environmental behavior that directly contributes to the environment.

\subsection{Environmental Consciousness and Eco-Friendly Behavior}

Consumers' awareness of environmental problems can be regarded as individual interest and consciousness of environmental problems. In other to, environmental consciousness is the degree of consciousness or interest that can move one's attitude to act in order to recognize environmental problems and preserve and improve them. Blake[6] emphasized that environmental consciousness is 'a problem of market competition that affects not only environmental activists' ideology but also consumer behavior'.

According to the previous studies comparing the difference of consumer's behavior according to environmental consciousness, the relationship between environmental consciousness and eco-friendly behavior was high, and consumers with high environmental consciousness were likely to do eco-friendly behavior[7]. Consumers with high sensitivity to environmental pollution, environmental reports, and articles claimed that the consistency of attitude and behavior appeared in the relationship between environmental preservation attitude and eco-friendly behavior[8]. Tognacci et al.,[9] also argued that environmental consciousness is an important factor in predicting eco-friendly behavior. There was a correlation between environmental consciousness and eco-friendly behavior.

\subsection{Environmental Attitude and Eco-Friendly Behavior}

According to Ajzen \& Fishbein[10], the attitude of an individual means a favorable or unfavorable evaluation of an uncertain being. Attitude is a learned temperament that consistently responds to given objects favorably or unfavorably[11]. Therefore, the perception of consumers who evaluate the environment favorably and non-favorably can be said to be environmental attitude[9][11]. Hungerford[12] defined environmental attitude as one of the consumption behaviors related to human life.

In addition, the study of Sauer \& Ruttinger[13] found a significant relationship between interest in the environment and water consumption, and participants with eco-friendly attitudes showed saving behavior for water consumption. In addition, De Young[14] proved that attitude is an important antecedent to determine behavior, and that environmental attitude has a positive relationship with environmental behavior. 


\subsection{Cultural Background}

Humans learn group norms and social roles during the growth process, and they are greatly influenced by the structure, system and culture of the society that belongs to this process[15]. Especially, environmental problems are deeply rooted by traditional values, attitudes, and perceptions spread to society[16] and attitudes and behaviors toward the environment can be expressed differently depending on the cultural characteristics of the own country[17]. Research on environmental attitudes and behaviors that are expressed differently according to race or ethnicity needs to be treated importantly to enhance the explanatory power of environmental behavior theory and to seek generalization of theory. In addition, the study considering racial and ethnic factors can contribute to enhance the effectiveness of environmental education or environmental policy aimed at improving the environmental behavior of citizens by predicting the phenomenon that occurs when individual psychological factors and social and cultural factors are combined in advance. Therefore, it is necessary to compare the environmental attitude and behavior among countries[17][18].

Johnson[17] and Laroche[18] conducted a study on differences in environmental behavior among ethnic groups. Johnson[17] studied the difference between environmental behavior among ethnic groups in white, black, Latino, and Asian populations. Laroche et al.,[18] confirmed that there was a difference in environmental behavior according to race even if the countries belonging to French Canadian and British Canadian populations were the same.

Hofstede[19] explained that the unique behavior pattern was due to the difference between collectivism and individualism among the cultural backgrounds of the country. At this time, collectivism society defined that group interests are given priority over individual interests, and that individualism society is a society that prioritizes individual interests over group interests.

Through previous studies, China was identified as a country with a strong tendency to collectivism[8]. China, a socialist system, has a very strong tendency to comply with and follow the government's decisions. It can be explained through the results such as moving factories to specific areas after the enactment of the New Environmental Act[1]. Either, Korea is geographically similar to China and has a characteristic that is known to be influenced by the surrounding people, and it is especially sensitive to subjective norms[7].

\section{Research Model and Research Question}

As examined through previous studies, this study aimed to examine the influence of 
environmental consciousness and environmental attitude as an antecedent variable for environmental behavior. In addition, the study was conducted by setting the target of the study as a consumer of Korea and China, not as a single country. In addition, to examine the differences by country, the influence of eco-friendly behavior according to cultural background was also examined.

As the research model of [Fig. 1], five research questions were set for this study.

Q1: Is there any difference in environmental consciousness between Korean and Chinese consumers?

Q2: Is there any difference in environmental attitude between Korean and Chinese consumers?

Q3: Is there any difference in cultural background between Korean and Chinese consumers?

Q4: Is there any difference in eco-friendly behavior between Korean and Chinese consumers?

Q5: How do the antecedent variables affect the eco-friendly behavior of Korean and Chinese consumers?

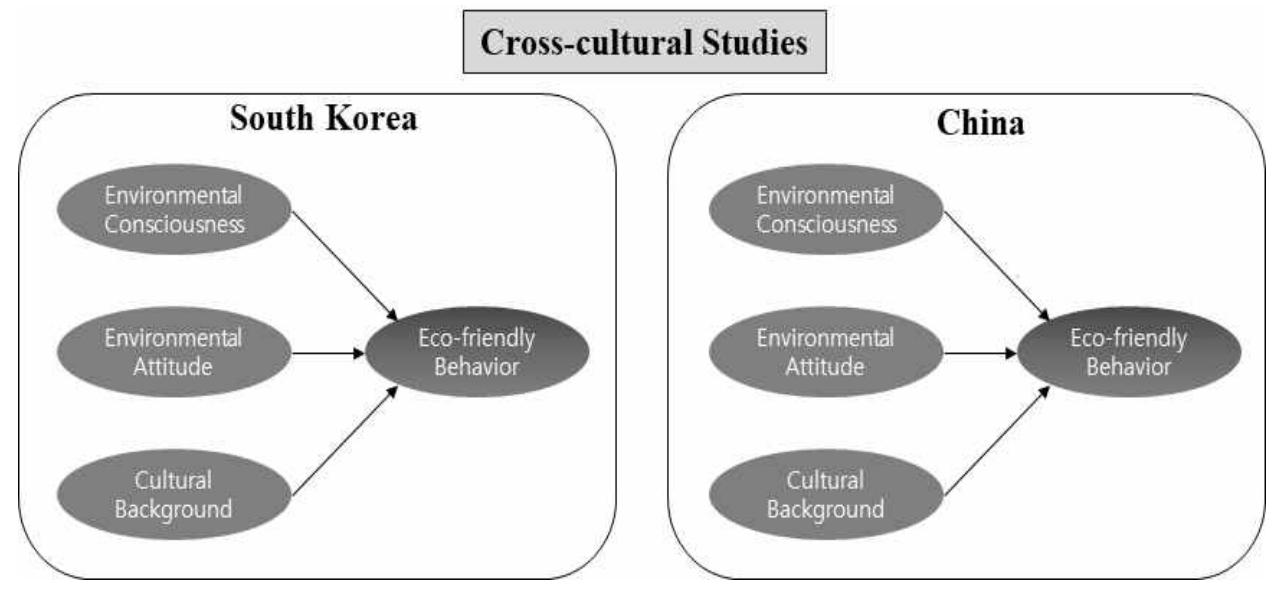

[Fig. 1] The Conceptual System for this Study

\section{Study method}

This paper is to verify whether there is a difference in the influence relationship between eco-friendly behavior and antecedent variables for consumers in Korea and China. Convenience samples were extracted from consumers in Korea and China, and self-recording online survey was conducted. The survey was conducted from December 1st to December 10th, 2018, and the survey was conducted from December 2nd to December 11th, 2018. A total of 210 were used 
for the final analysis in Korea except for unfaithful responses, and 198 were used for the analysis in China. The collected data were analyzed using SPSS program and frequency analysis was conducted to understand demographic characteristics. To verify the reliability and validity of the variables, Cronbach's a was confirmed and confirmatory factor analysis was conducted. In addition, t-test was conducted to verify the difference of antecedent variables on eco-friendly purchasing behavior of Korean and Chinese consumers, and the influence of antecedent variables on dependent variables was empirically analyzed through regression analysis.

\section{Result}

\subsection{A Demographic Analysis of the Subjects}

The demographic variables were composed of gender, age, education, occupation, and monthly income. First, in Korea, 107 men and 126 women were male and 210 women were female. The number of Chinese respondents was 97 among 198, and 101 were male. The frequency and percentage of the respondents were slightly higher in both countries.

[Table 1] Consumer Profile and Frequency Information

\begin{tabular}{|c|c|c|c|c|c|}
\hline & & \multicolumn{2}{|c|}{ South Korea $(n=210)$} & \multicolumn{2}{|c|}{ China $(n=198)$} \\
\hline & & Frequency & Percent & Frequency & Percent \\
\hline \multirow{2}{*}{ Gender } & man & 107 & 50.95 & 97 & 48.99 \\
\hline & woman & 103 & 49.05 & 101 & 51.01 \\
\hline \multirow{4}{*}{ Age group } & $20 \mathrm{~s}$ & 84 & 40 & 85 & 42.93 \\
\hline & $30 \mathrm{~s}$ & 57 & 27.14 & 45 & 22.73 \\
\hline & $40 \mathrm{~s}$ & 43 & 20.48 & 41 & 20.71 \\
\hline & 50 s & 26 & 12.38 & 27 & 13.64 \\
\hline \multirow{3}{*}{$\begin{array}{c}\text { Educational } \\
\text { level }\end{array}$} & High school or below & 35 & 16.67 & 89 & 44.95 \\
\hline & Bachelor degree & 152 & 72.38 & 47 & 23.74 \\
\hline & Master degree or above & 23 & 10.95 & 62 & 31.31 \\
\hline \multirow{3}{*}{ Job } & Student & 78 & 37.14 & 68 & 34.34 \\
\hline & Professional & 21 & 10 & 39 & 18.57 \\
\hline & Self-employed & 28 & 13.33 & 27 & 13.64 \\
\hline
\end{tabular}




\begin{tabular}{|c|c|c|c|c|c|}
\hline & Office worker & 63 & 30 & 38 & 19.19 \\
\cline { 2 - 6 } & Service & 10 & 4.76 & 14 & 7.07 \\
\cline { 2 - 6 } & Housewife or etc & 10 & 4.76 & 12 & 6.06 \\
\hline \multirow{4}{*}{$\begin{array}{c}\text { Monthly } \\
\text { income } \\
\text { (Korea won) }\end{array}$} & Less than 1,500,000 & 79 & 37.61 & 39 & 19.70 \\
\cline { 2 - 6 } & $1,500,000 \sim 3,000,000$ & 47 & 22.38 & 72 & 36.36 \\
\cline { 2 - 6 } & $3,000,000 \sim 4,500,000$ & 59 & 28.10 & 43 & 21.71 \\
\cline { 2 - 6 } & $4,500,000 \sim 6,000,000$ & 10 & 4.76 & 20 & 10.10 \\
\hline
\end{tabular}

\subsection{Reliability and Validity Verification Result}

For the validity, factor analysis was conducted on the survey results of consumers in Korea and China. Factor analysis was conducted on environmental consciousness, environmental attitude, cultural background and eco-friendly behavior items suggested to measure variables. As a result, the value of the questions in both countries was over .50 and was appropriately tied up, which means that the validity of the scale composition was confirmed. Cronbach's a was calculated to verify the reliability of the scale used in this study. As a result of the analysis, the value of Cronbach's a for all variables was secured by satisfying the general reliability standard of .60 .

\subsection{Research Question verification}

To examine the difference between environmental consciousness, environmental attitude, cultural background and eco-friendly behavior of Korean and Chinese consumers, T-test was conducted. The result was [Table 2].

The first research question was to find out whether there is a difference in environmental consciousness between Korean and Chinese consumers. The t-value was 7.301 and there was a significant difference. The second research question is whether there is a difference in the environmental attitude between Korean and Chinese consumers. As shown in the table, $t$-value was 5.494, which showed a significant difference. Korean consumers showed a higher favorable attitude toward the environment.

In the research question 3, whether there is a difference according to cultural background, the $t$ value was 5.016, which was confirmed to be a significant difference. Especially, it was confirmed that Chinese consumers are more affected by cultural background variables. 
The fourth research question was to examine whether there is a difference in eco-friendly behavior between Korean and Chinese consumers, and $t$ value was 2.431, which showed a significant difference. It was confirmed that Chinese consumers were more active in the environmental behavior variables.

[Table 2] Results of T-test

\begin{tabular}{|c|c|c|c|c|c|}
\hline \multicolumn{2}{|c|}{ Variables } & Mean & Std. Dev. & $\mathrm{t}$-value & $\mathrm{P}$ \\
\hline \multirow{2}{*}{$\begin{array}{l}\text { Environmental } \\
\text { Consciousness }\end{array}$} & South Korea & 4.601 & .543 & \multirow{2}{*}{7.301} & \multirow{2}{*}{0.000} \\
\hline & China & 4.213 & .589 & & \\
\hline \multirow{2}{*}{$\begin{array}{c}\text { Environmental } \\
\text { Attitude }\end{array}$} & South Korea & 4.277 & .725 & \multirow{2}{*}{5.493} & \multirow{2}{*}{0.000} \\
\hline & China & 3.985 & .502 & & \\
\hline \multirow{2}{*}{$\begin{array}{c}\text { Cultural } \\
\text { Background }\end{array}$} & South Korea & 2.574 & .976 & \multirow{2}{*}{5.016} & \multirow{2}{*}{0.000} \\
\hline & China & 2.986 & .776 & & \\
\hline \multirow{2}{*}{$\begin{array}{l}\text { Eco-friendly } \\
\text { Behavior }\end{array}$} & South Korea & 3.021 & .819 & \multirow{2}{*}{2.431} & \multirow{2}{*}{0.020} \\
\hline & China & 3.310 & .597 & & \\
\hline
\end{tabular}

Lastly, the research question 5 was to confirm the difference in the degree of influence on the eco-friendly behavior of Korean and Chinese consumers. To confirm this, the eco-friendly behavior was used as a dependent variable, and the environmental consciousness, environmental behavior, and cultural background were used as independent variables.

The results of regression analysis on eco-friendly behavior of Korean and Chinese consumers are as follows.

[Table 3] Regression Analysis of Eco-Friendly Behavior

\begin{tabular}{|c|c|c|c|c|c|c|}
\hline \multirow{2}{*}{ Variables } & \multicolumn{3}{|c|}{ South Korea } & \multicolumn{3}{c|}{ China } \\
\cline { 2 - 7 } & Std. Coef. & $\mathrm{t}$-value & $\mathrm{P}$ & Std. Coef. & t-value & $\mathrm{P}$ \\
\hline $\begin{array}{c}\text { Environmental } \\
\text { Consciousness }\end{array}$ & .023 & .358 & .821 & -.037 & -.437 & .680 \\
\hline $\begin{array}{c}\text { Environmental } \\
\text { Attitude }\end{array}$ & .180 & 4.244 & .001 & 005 & .065 & .873 \\
\hline $\begin{array}{c}\text { Cultural } \\
\text { Background }\end{array}$ & .657 & 10.765 & .000 & .435. & 7.243 & .000 \\
\hline
\end{tabular}

* South Korea : modified R squre $=.576, \quad F=71.421(p<.0001)$

* China : modified $\mathrm{R}$ squre $=487, \mathrm{~F}=41.3021(\mathrm{p}<.0001)$

As a result of regression analysis on green purchasing behavior of Korean consumers, environmental attitude and cultural background had a significant effect on eco-friendly 
behavior, but environmental consciousness had no significant effect. The explanatory power of these independent variables on eco-friendly behavior was $57.6 \%$. On the other hand, the results of regression analysis on green purchasing behavior of Chinese consumers showed that cultural background had a significant effect, but environmental consciousness and environmental attitude had no significant effect. The explanatory power of the independent variable on the green buying behavior was $48.7 \%$. As a result of comparing Korea and China through regression analysis, environmental attitude had an effect on eco-friendly behavior in Korea, but environmental attitude of Chinese consumers did not have an effect on eco-friendly behavior.

In the case of cultural background, Korea is .657 and China is .435. And the degree of influence on environmental behavior of environmental consciousness was not statistically significant in both Korea and China.

\section{Discussion and Conclusion}

This study compared the difference of eco-friendly behavior according to environmental knowledge, environmental attitude and cultural background of Korean consumers living in Seoul and Chinese consumers living in Shanghai. Based on the variables, the difference in the influence of Korean and Chinese consumers on the eco-friendly behavior was also examined. The results of this study are as follows.

First, Korean and Chinese consumers' environmental consciousness and attitude toward the environment were all high, and Korean consumers' environmental consciousness and attitude were higher than Chinese consumers. The reason for this result is that in Korea, the contents of environmental education are included from the curriculum, and the daily life is exposed to environmental consciousness by repeating the experience of separating and discharging recycled garbage every week.

Second, the influence on cultural background was shown to be higher in Chinese consumers. As confirmed through previous studies, this figure is expected to be influenced by the cultural background of China, which has a strong tendency to collectivism. Especially, it can be inferred that China under the socialist system can have a stronger influence than Korea.

Third, a significant difference in eco-friendly behavior between the two countries has been found. Chinese consumers take more eco-friendly actions than South Korean consumers, a report showed. The result can be inferred from the low tendency of consciousness to act, such as a leading study that suggests that Korean consumers do not do actual actions even if they are highly environmentally conscious[7]. On the other hand, in the case of China, the results 
are expected to be the result of the majority of the people trying to keep the government's measures, especially since they are more inclined to consume certain government-designated products, depending on the cultural background of being under the socialist system.

Finally, it was compared whether there is a difference in the influence of antecedent variables on eco-friendly behavior of Korean and Chinese consumers. As a result, it was found that environmental attitude had an effect on eco-friendly behavior in Korean consumers, but it did not affect Chinese consumers. Rather, the influence of cultural background on eco-friendly behavior was stronger in Korea, and in the case of environmental consciousness variables, both Korea and China were not statistically significant.

The study compared South Korean and Chinese consumers, but I think research involving wider regional distribution and age groups will have to be conducted to confirm the more generalized results. And at the same time, further studies also expect that more diverse cultural and social variables will be added to enable deeper and meaningful discoveries if we look at the various variables and their impact on eco-friendly consumer behavior. Despite these limitations, the comparative culture study through academic approach found a significant difference between Korean and Chinese consumers in eco-friendly behavior. The results of this study can be used as basic data for environmental policies of each country. It is also expected that the direction of the company's eco-friendly marketing strategy will have a positive impact.

\section{Acknowledgement}

This study was supported by the Ewha Womans University scholarship of 2018.

\section{References}

[1] Han, S. H., The recent trend of Environmental Protection Law in China -Focus on Problems and Resolutions, Environmental Law Review, (2018), Vol.40, No.1, pp.193-220, DOI: 10.35769/elr.2018.40.1.006

[2] https://m.post.naver.com/viewer/postView.nhn?volumeNo=18112872\&memberNo=45200987\&vType=VERTICAL, Mar 7 (2019)

[3] https://blog.naver.com/kecoprumy/221550519675, May 30 (2019)

[4] Kaiser, F. G. \& Urs, F., Ecological behavior's dependency on different forms of knowledge, Applied Psychology, (2003), Vol.52, No.4, pp.598-613, DOI: https://doi.org/10.1111/1464-0597.00153

[5] Kaman, L., Genader differences in Hong Kong adolescent consumers' green purchasing behavior, Journal of Consumer Marketing, (2009), Vol.26, No.2, pp.87-96, DOI: 10.1108/07363760910940456 
[6] Blake, D. E., Contextual effects on environmental attitudes and behavior, Environment and Behavior, (2001), Vol.33, No.5, pp.708-725, DOI: 10.1177/00139160121973205

[7] Yoon, J., A study on a eco-friendly product purchase process using expanded theory of planned behavior, Ewha Womans University, Ph. D. Dissertation, (2019), pp.1-136.

[8] Yoon, J., Joung, S., A Study of Purchase Intention of Eco-friendly Products: A Cross-Cultural Investigation between Korea and China, International Journal of Smart Business and Technology, (2019), Vol.7, No.2, pp.19-24.

[9] Tognacci, L. N., Weigal, R. H., Wilden, M. F. Vernon, D. T., A, Environmental Quality: How Universal is public concern?, Environment and Behavior, (1972), Vol.4, No.1, pp.73-86, DOI: https://doi.org/10.1177/001391657200400103

[10] Ajzen. I., Fishbein. M, Attitude-Behavior relations: A theoretical Analysis and review of empirical research, Psychological Bulletin, (1977), Vol.84, No.5, pp.888-918, DOI: 10.1037/0033-2909.84.5.888

[11] Lucy, J. H., Taciano. L. M., The use (and abuse) of the new environmental paradigm scale over the last 30 years: A meta-analysis, Journal of Environmental Psychology, (2009), Vol.30, No.2, pp.143-158, DOI: 10.1016/j.jenvp.2009.10.003

[12] Hungerford, H. R., Volk, T. L., Changing learner behavior through environmental education, The Journal of Environmental Education, (1990), Vol.21, No.3, pp.8-21, DOI: 10.1080/00958964.1990.10753743

[13] Sauer, J, Bruno R, Environmental Conservation in the Domestic Domain: The Influence of Technical Design Features and Person-Based Factors, Ergonomics, (2004), Vol.47, No.10, pp.1053-1072, DOI: $10.1080 / 00140130410001686302$

[14] De Young, R., Exploring the Difference between Recylers and Non-Recyclers: The Role of Information, Journal of Environmental Systems, (1989), Vol.18, No.4, pp.341-351, DOI: 10.2190/FBQC-5V5D-HHVC-V6X8

[15] Bock, P. K., Modern Cultural Anthropology: An Introduction, Jeonghoon Publishing, (1993)

[16] J. Deng, G. J. Walker, G. Swinnerton, A comparison of environmental values and attitudes between Chinese in Canada and Anglo-Canadians, Environment and Behavior, (2006), Vol.38, No.1, pp.22-47, DOI:10.1177/0013916505278458

[17] C. Y. Johnson, J. M. Bowker, H. K. Cordell, Ethnic variation in environmental belief and behavior: An examination of the new ecological paradigm in a social psychilogical context, Environment and Behavior, (2004), Vol.36, No.2, pp.157-186, DOI: https://doi.org/10.1177/0013916503251478

[18] M. Laroche, M.-A. Tomiuk, J. Bergeron, G. Barbaro-Forleo, Cultural differences in environmental knowledge, attitudes, and behaviors of Canadian consumers, Canadian Journal of Administrative Sciences, (2009), Vol.19, No.3, pp.267-282, DOI: 10.1111/j.1936-4490.2002.tb00272.x

[19] G. Hofstede, G. J. Hofstede, M. Minkov, Cultures and Organizations: Software of the Mind, McGraw Hill, (1991) 